The Journal of Vitaminology 11, 153-158 (1965)

\title{
ACTIVITY OF CARBETHOXYTHIAMINE AND THIAMINE PROPYL DISULFIDE ON KLOECKERA APICULATA ${ }^{1}$
}

\author{
CHIKATARO KAWASAKI AND SUMIO SHINODA ${ }^{2}$ \\ School of Pharmacy, Osaka University, Toyonaka
}

(Received March 8, 1965)

Carbethoxythiamine stimulates the growth of a thiamine-requring mutant, Kloeckera apiculata IFO No. 0630, more than thiamine-HCl. To clarify the reason, various behaviors of CET toward K. apiculata was investigated by the authors $(1,2)$. Asymmetrical thiamine disulfide derivatives, such as TPD, promate the growth of $K$. apiculata like CET more than thiamine (3). In this paper, the behavior of CET toward the growth of K. apiculata is compared with that of TPD.

\section{EXPERIMENTAL}

\section{Culture of K. apiculata}

To $2 \mathrm{ml}$ of the medium improved by Hoff-J $\not$ rgensen (5), as described by the author (4), the samples were added aseptically in a total volume of $4 \mathrm{ml}$. The cells were inoculated to the medium with a hypodermic syringe with a needle, $1 / 3 \mathrm{~mm}$ in diameter. After incubation at $30^{\circ}$ for 20 hours, the growth of the cells was measured spectrophotometrically as the optical density at $610 \mathrm{~m} \mu$, using Hitachi Spectrophotometer.

\section{Samples}

Thiamine, CET, CBT and TPD, each as hydrochloride, were dissolved in sterilized distilled water.

\section{Determination of TPD and CET}

TPD was reduced to thiamine by cysteine treatment and the thiamine thus produced was determined as thiochrome by the $\mathrm{BrCN}$ method. CET was treated with alkali (7) and the thiamine thus produced was determined by the $\mathrm{BrCN}$ method.

\section{RESULTS}

1. Activities of CET, CBT and Thiamine Treated with Takadiastase As CET and CBT are known to be easily reduced to thiamine by Takadiastase

1 The Growth-stimulating Activity of Thiamine Derivatives on Thiamine-requiring Microorganisms. XI. Following abbreviations are used: CET, carbethoxythiamine; TPD, thiamine propyl disulfide; CBT, $S$-carbobutoxythiamine.

2 川崎近太郎, 篠田純男。 
$(6,7)$, both derivatives were treated with Takadiastase to be converted into thiamine and the activities were compared with that of thiamine as follows. To $2 \mathrm{ml}$ of the medium, CET, CBT or thiamine, equivalent to $0.02-0.1 \mu \mathrm{g}$ thiamine, is added and, in addition, Takadiastase B (thiamine was removed by adsorption on acid clay) is added to give a final concentration of $250 \mathrm{mg}$ per $100 \mathrm{ml}$ in a total volume of $4 \mathrm{ml}$. The mixtures were incubated at $37^{\circ}$ for 24 hours. Thereafter they were heated at $100^{\circ}$ for 15 minutes for sterilization of the bacteria contaminated in Takadiastase solution and after cooling, the bacteria were inoculated (Fig. 1, A). The control test was made in the same way but without Takadiastase treatment (Fig. 1, B).

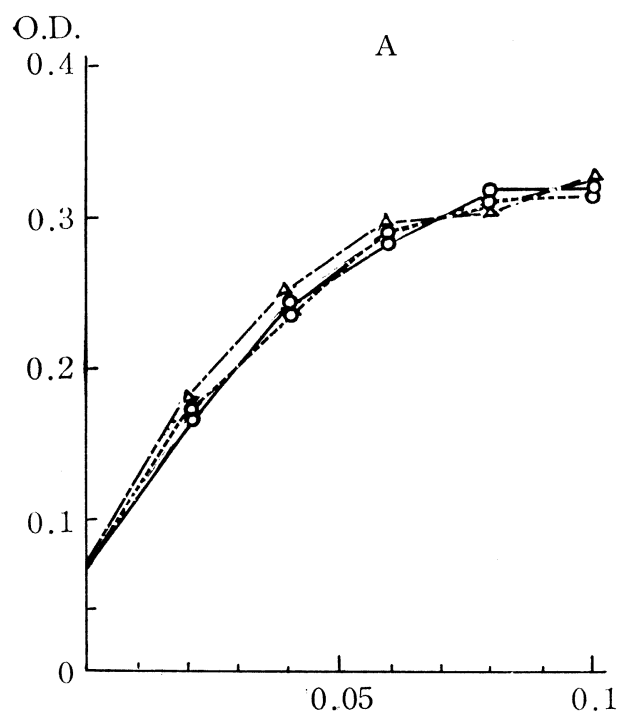

Amount corresponding to $\mu \mathrm{g}$ thiamine per tube

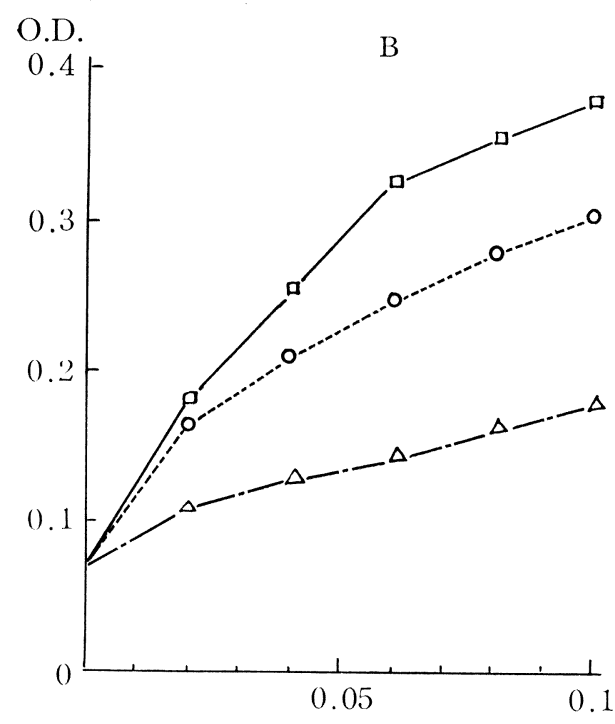

Amount corresponding to $\mu \mathrm{g}$ thiamine per tube

FIG. 1 Activity of CET, CBT and Thiamine after Takadiastase Treatment on the Growth of K. apiculata

A, inoculation was made after incubation at $37^{\circ}$ for $24 \mathrm{hr}$ with $250 \mathrm{mg}$ Takadiastase per $100 \mathrm{ml}$

$\mathrm{B}$, inoculation was made without Takadiastase treatment.

$O$, thiamine; $\square, \mathrm{CET} ; \triangle, \mathrm{CBT}$.

Without Takadiastase treatment, the activity showed in the decreasing order of CET, thiamine, CBT, but after conversion to thiamine by Takadiastase all showed the same activity.

\section{Activity of TPD Treated with Cysteine}

To $2 \mathrm{ml}$ of the medium, cysteine hydrochloride was added up to a final concentration of $50 \mathrm{mg}$ per $100 \mathrm{ml}$. After sterilization the samples were added in a total volume of $4 \mathrm{ml}$. The mixtures were heated at $60^{\circ}$ for 30 minutes to reduce TPD to thiamine. After inoculation, the whole were incubated at $30^{\circ}$ for 20 hours (Fig. 2, A). The control tests were made with inoculation of the medium, but without heating at $60^{\circ}$ for 30 minutes (Fig. 2, B). TPD showed, however, differing from CET, stronger stimulation of the growth than thiamine, though TPD had 


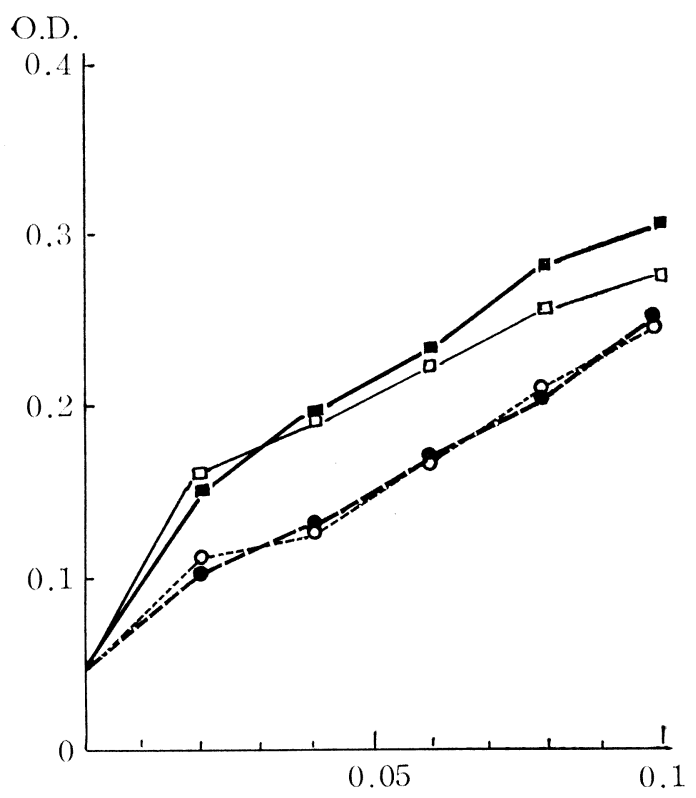

Amount corresponding to $\mu \mathrm{g}$ thiamine per tube

Fia. 2 Activity of TPD and Thiamine Treated with Cysteine on the Growth of $K$. apiculata

A, inoculation was made after treatment with $50 \mathrm{mg}$ cysteine per $100 \mathrm{ml}$ at $60^{\circ}$ for $30 \mathrm{~min}$.

$\mathrm{B}$, inoculation was made without cysteine treatment.

$\square$, TPD (A); $\mathbf{a}$, TPD (B); O, thiamine (A); $\bullet$, thiamine (B).

been converted to thiamine extracelluarly. TPD equivalent to $1 \mu \mathrm{g}$ thiamine produced $102 \%$ thiamine after cysteine treatment under the same condition as described above. Therefore, TPD given in Fig. 2, $\mathrm{A}$ is assumed to have completely converted to thiamine after cysteine treatment. Cysteine is known to inhibit the growth of $K$. apiculata, but it was very slight at this concentration.

\section{Growth of the Cells Accumulated with TPD or Thiamine}

CET was taken up by the cells in the saline. If the cells thus treated were diulted with the medium and were incubated, it showed the activity greater than thiamine treated similarly (2). The same test was made with TPD as follows. To the cell suspension in saline (containing $30 \mathrm{mg}$ dry weight of cells), TPD or thiamine, corresponding to $10 \mu \mathrm{g}$ thiamine, was added in a total volume of $5 \mathrm{ml}$. The mixtures were heated at $30^{\circ}$ for 30 minutes. With this treatment, TPD or thiamine added to the suspension was completely accumulated in the cells and TPD was reduced to thiamine. A part of the suspension was centrifuged and the cells were washed twice with saline and suspended in the medium (Fig. 3, A). The other part of the suspension was diluted immediately with saline (Fig. 3, B) without centrifugation. The suspensions containing the vitamin, equivalent to $0.01-0.08 \mu \mathrm{g}$ thiamine, were cultured at $30^{\circ}$ for 20 hours. TPD, accumulated in the cells being 
O.D.

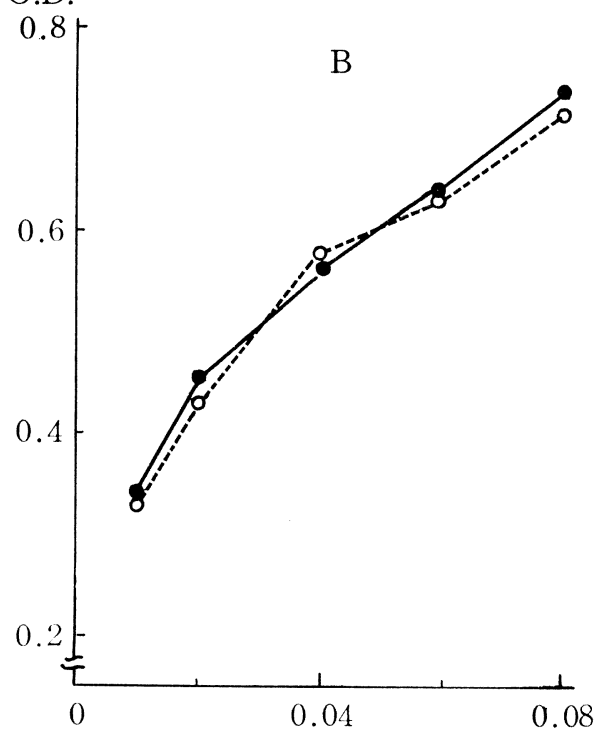

O.D.

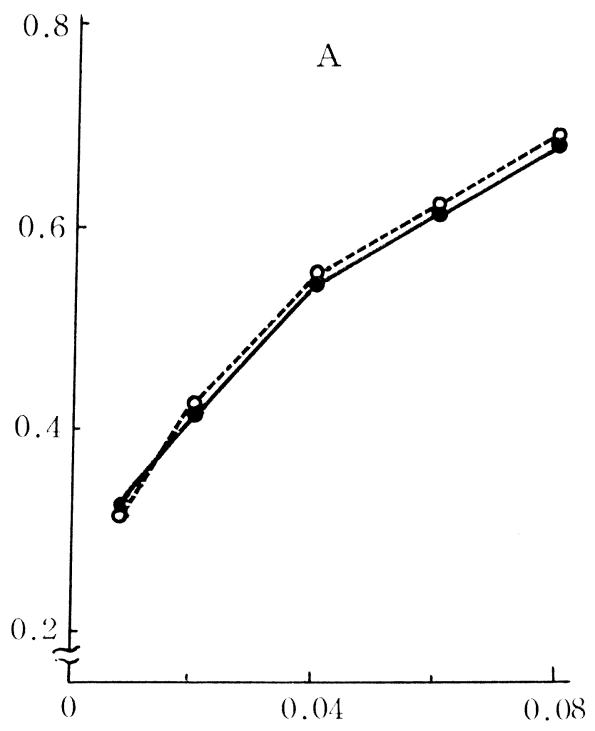

Amount corresponding to $\mu \mathrm{g}$ thiamine per tube

FIs. 3 Growth of $K$. apiculata Accumulated TPD or Thiamine

A, after accumulation of the vitamin in saline, the cells are collected and washed and diluted with the medium

$B$, after accumulation of the vitamin in saline, the cells are diluted with the medium without centrifugation.

$\bigcirc$, thiamine; $\bullet$, TPD.

suspended in saline, showed the same activity as thiamine irrespective of the treatment of centrifugation and washing, a behavior quite different from CET,

4. Activity of TPD) and Thiamine on K. apiculata (Effects of the Amounts of the Cells Inoculated)

That TPD showed the same activity on the growth of $K$. apiculata as thiamine may be due to the fact that more cells were inoculated than in the ordinary culture. On the other hand, it was observed in the culture of Lactobacillus fermenti 36 that the difference of the activities between TPD and thiamine was the more marked, the less bacteria were inoculated (8). The effects of the amounts of the inoculated Kloeckera were therefore investigated as follows. To the medium containing TPD or thiamine equivalent to $0.05 \mu \mathrm{g}$ thiamine, the cells 0.1 to $10^{3}$ times the amount usually empolyed were inoculated and the whole were cultured at $30^{\circ}$ for 20 hours (Fig. 4). In the experiment given above (Fig. 3), the yeast about 10 to 100 times the amount usually employed was used. Within this range, TPD showed definitely greater activity than thiamine.

\section{Reduction of TPD and CET to Thiamine by Cell Suspension}

To the cell suspension in saline containing the bacteria (about $10 \mathrm{mg}$ as dry weight) was added TPD or CET equivalent to $10 \mu \mathrm{g}$ thiamine and the whole was 


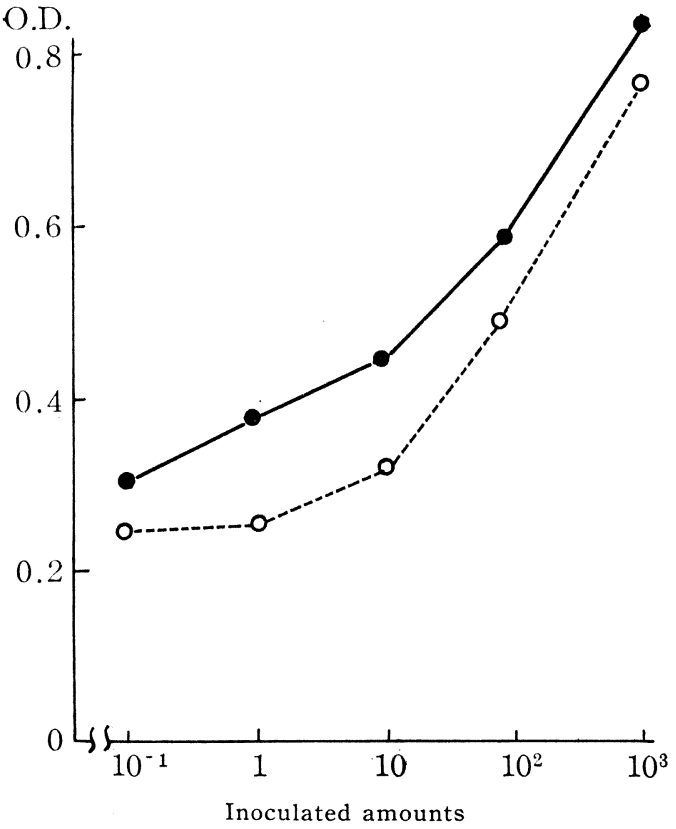

Fig. 4 Activity of TPD and Thiamine on the Growth of K. apiculata (Effects of the Amounts of Inoculated Cells)

Amounts of TPD and thiamine: equivalent to $0.05 \mu \mathrm{g}$ thiamine per tube.

$\bigcirc$, thiamine; $\bullet$, TPD.

incubated at $\mathrm{pH} 4.7$ and $30^{\circ}$. After a certain period, the reaction was stopped by addition of $5 \mathrm{ml} 10 \%$ metaphosphric acid, and the thiamine in the cells was extracted for 10 minutes in a boiling water bath. After centrifugation, the supernatant was assayed for free and total thiamine including TPD and CET (Table 1). Remarkable differences were observed between the conversion of TPD and CET into thiamine; TPD was completely reduced to thiamine but CET was a little reduced.

TABLE 1

Fcrmation of Thiamine from TPD and CET by Cell Suspension

Amounts of TPD and CET, equivalent to $10 \mu \mathrm{g}$ thiamine; cells, $10 \mu \mathrm{g}$ (dry weight); total volume, $5 \mathrm{ml} ; 30^{\circ}, \mathrm{pH} 4.7$.

\begin{tabular}{ccccccc}
\hline & \multicolumn{7}{c}{ Iucubation time (min) } \\
\cline { 2 - 6 } & 0 & 20 & 40 & 60 & 80 & 100 \\
\hline \multirow{2}{*}{ TPD } & 11 & 96 & 95 & 97 & 98 & 94 \\
& $(98)^{a}$ & $(94)$ & $(96)$ & $(96)$ & $(98)$ & $(96)$ \\
\hline \multirow{2}{*}{ CET } & 0 & 7 & 7 & 8 & 9 & 12 \\
& $(96)^{a}$ & $(95)$ & $(99)$ & $(96)$ & $(100)$ & $(94)$ \\
\hline
\end{tabular}

a Total thiamine estimated including TPD or CET. 


\section{DISCUSSION}

Both TPD and CET were shown to stimulate the growth of $K$. apiculata more than thiamine, but the behaviors of the two toward the yeast were different. CET and CBT showed the same activity as thiamine when they were reduced to thiamine extracellularly, whereas TPD showed the activity greater than thiamine, when it was converted to thiamine extracellularly. Both of them became active after conversion to thiamine. Therefore, the propylmercapto or carbethoxy radical which was produced during conversion to thiamine, is assumed to be effective for the growth. From the findings of the authors it is assumed that the propylmercapto group was effective extracellularly and carbethoxy radical intracellularly. But it is to be noted that CET was heat-sterilized after Takadiastase treatment. If the carbethoxy group is evaporated by heat sterilization, the above assumption may be untenable. To avoid the contamination in Takadiastase preparation, the suspension was sterilized after Takadiastase treatment, but the effect may be clarified by comparing the suspension after aseptic addition of CET-degrading enzyme. When the cells in which CET and TPD had been accumulated in saline were diluted with the medium, CET showed the activity greater than thiamine (2), but TPD was as active as thiamine. It may be due to the fact that TPD was easily reduced to thiamine by the contact with the cells in saline. It is a good contrast to the finding that TPD showed the activity greater than thiamine, when it was reduced in the medium. CET is hardly reduced to thiamine in saline, but was gradually reduced in the medium when the cells were in the accelerated growth $(1,2)$. It was thus concluded that TPD and CET stimulate the growth of $K$. apiculata but each of them behaves differently in the mechanism of growth-stimulation.

\section{SUMMARY}

Both thiamine propyl disulfide (TPD) and $S$-carbethoxythiamine (CET) stimulate the growth of $K$. apiculata but they show the following different behaviors.

1. When CET is reduced to thiamine extracellularly by Takadiastase, it shows the same activity as thiamine on the growth of the bacterium.

2. When TPD is reduced to thiamine by cysteine extracellularly, it shows the activity greater than thiamine.

3. When TPD accumulated in the cells in saline are diluted with the medium and incubated, they show the same activity as thiamine, but when CET is treated in the same way, it showes the activity greater than thiamine.

4. TPD is easily reduced to thiamine in the presence of the yeast suspension but CET is slowly converted to thiamine on the same treatment.

\section{REFERENCES}

1. Kawasaki, C., Hiraoka, E. and Shimamoto, T, Vitamins, 28, 295 (1963).

2. Kawasaki, C. and Shinoda, S., Vitamins 28, 299 (1963).

3. Kawasaki, C. and Yamada, C., Vitamins 28, 290 (1963).

4. Kawasaki, C., Hiraoka, E. and Shimamoto, T., Vitamins 22, 387 (1961).

5. Hoff-J $\phi$ rgensen, E and Hansen, B., Acta Chem. Scand. 9, 562 (1955).

6. Kawasaki, C., Ono, Y. and Shinoda, S., Vitamins 25, 520 (1962).

7. Yamamoto, R., Inazu, K. and Shima, K., Vitamins 25, 478 (1962).

8. Kawasaki, C., Ichikawa, T., Shinoda, S. and Morishita, Y., Vitamins 3089 (1964). 